\title{
Rewarded responding under inescapable stress and later performance under stress'
}

\author{
K. M. SHEMBERG, DEPARTMENT OF PSYCHOLOGY, \\ BOWLING GREEN STATE UNIVERSITY, Bowling Green, Ohio \\ 43402
}

The effects of learning to perform a rewarded bar-press response under inescapable shock upon later performance under inescapable shock were studied. Rats underwent one of three treatments. bar-press for water during inescapable shock $(R R)$, yoked shock control $(S C)$, or no-treatment control $(C)$. The $S$ s then learned to panel-press for food, and were subsequently tested to determine the degree to which inescapable shock interfered with panelpressing. The Ss in the RR group were less disrupted than SC or $C$ $S s$, and $C S s$ were the most disrupted. The possibility of results being mediated by a learned expectancy was suggested.

There has been an increasing interest in the effects of escapable vs inescapable stress upon later performance under stress. While the data are not completely consistent, it has often been found that Ss who learn to escape stress are less disrupted in later stress situations than are Ss who experience inescapable stress (Gauron, 1964; Seligman \& Maier, 1967; Overmeir \& Seligman, 1967). The present research focuses upon the relationship between inescapable stress and later performance under stress. The specific question asked is: what are the effects of learning to bar press for water reward during inescapable shock upon the later performance of a panel-press for food response under inescapable shock?

Some theoretical notions are provided by the literature to suggest that Ss learning the rewarded bar-press response while experiencing inescapable shock will be less disrupted in a later stress situation than will Ss experiencing only inescapable shock. For example, it has been suggested that the performance of certain instrumental responses, like eating, reduces behavioral and physiological fear responses (Farber, 1948; Pavlov, 1927). From this point of view it is possible to argue that the reinforcement attending such reductions in fear increases the probability that other ongoing rewarded responses will be performed in later inescapable stress situations. Similarly, Shemberg (1966) has suggested that learning to perform a rewarded response in inescapable stress situations results in the inhibition of incompatible and ineffective escape responses in later stress situations. This inhibition may be based upon the learned expectancy that the continuation of ongoing behavior will lead to rewards despite discomfort. Either one of these positions leads to the following prediction: learning to perform water rewarded, bar-press responses during inescapable shock will lead to less disruption in a later panel press for food response under inescapable shock than will experiencing inescapable shock alone.

Method. Subjects were 30 male Sprague-Dawley albino rats, approximately 75 days old, divided at random into the following groups: Rewarded responding ( $R R, N=10$ ), Shock control ( $S C, N=10$ ), Learning control (LC, $N=5)$, Control $(C, N=5)$. The experiment was carried out in two phases, a training phase (Phase 1) and a test phase (Phase 2). Apparatus for Phase 1 was two LVE 1578D cages with grids wired to a Grason-Stadler E1064GS shock generator. One cage included a LVE 1351 liquid dipper programmed to provide one dipper of water per lever press. The second cage contained no manipulanda. Apparatus for Phase 2 was a LVE 1578D cage supplied with a 2 in. $x 2$ in. panel which when pressed outward approximately $4 \mathrm{~mm}$ delivered one $20 \mathrm{mg}$ Noyes pellet. The grids of this cage were also wired to a E1064GS shock scrambler.

At the beginning of Phase 1 all Ss were placed on a five-day long, $23 \mathrm{~h}$, water deprivation schedule. This schedule was maintained throughout Phase 1. On the sixth day RR and LC Ss were trained for 30 min to lever press for water reward, and returned to home cages for $30 \mathrm{~min}$ of ad lib drinking. This procedure continued for 10 days. On the eleventh day of training RR Ss were allowed to lever press for $1 \mathrm{~min}$. During the remaining $29 \mathrm{~min} .05 \mathrm{~mA}$ of inescapable, scrambled shock was applied to the grids. This procedure continued for 13 days with systematic increases in shock. One day of training was given at each of the following shock intensities: $.05 \mathrm{~mA}, .06 \mathrm{~mA}, .08$ $\mathrm{mA}, .10 \mathrm{~mA}, .13 \mathrm{~mA}$. Two days of training were given at each of the following shock levels: $.16 \mathrm{~mA}, .20 \mathrm{~mA}, .30 \mathrm{~mA}$, and $.40 \mathrm{~mA}$.

Learning control (LC) Ss continued lever pressing over this shock training period with no shock being introduced. Shock control Ss (SC) were yoked to RR Ss, thus receiving equivalent time in the grid floor cage as well as equivalent shock experience. Group (C) Ss remained in home cages except for 5 min of daily handling.

Phase 1 was discontinued following the 13 days of rewarded responding under inescapable stress. All Ss then received four days ad lib food and water and were subsequently placed on a $23-\mathrm{h}$ food deprivation schedule.

On day one of Phase 2 all Ss were trained for $20 \mathrm{~min}$ to panel press for food reward and returned to home cages for $1 \mathrm{~h}$ food, ad lib. This procedure continued for 10 days with daily response rates recorded in terms of number of responses emitted and number of pellets eaten. On the eleventh day of Phase 2 the shock stress test was administered. Each S panel-pressed for 6 $\mathrm{min}$, and response rates and number of pellets consumed per minute were recorded. Then $6 \mathrm{~min}$ of $.40 \mathrm{~mA}$ continuous scrambled shock was introduced. The number of responses per minute and the number of pellets eaten per minute were recorded.

Results. There were no systematic differences among the groups regarding the acquisition of the panel press response. Analysis of shock test performance indicated no difference between the LC and C groups, suggesting that prior lever press training alone had no effect on later performance under stress. Therefore, LC and C groups were combined for the overall analysis.

The indicant of disruption under stress was eating behavior during the six unshocked minutes of the test as compared to eating behavior during the six shocked minutes. Response rates over the $6 \mathrm{~min}$ prior to shock were stable across all Ss, justifying the use of mean preshock response rates as an indication of eating behavior during no-stress periods. The mean response rate over the six shocked minutes was used as an overall index of performance during stress. A high correspondence existed between number of responses emitted and number of pellets eaten $(r=.89)$. Also, no systematic differences between number of pellets eaten and number of responses emitted occurred among the groups. Therefore, data analysis was performed upon number of responses only. A disruption score was derived for each $S$ comprised of the difference between mean number of responses emitted during the first $6 \mathrm{~min}$ of the test minus the mean number of responses occurring during the six shocked minutes.

Table 1 shows means and standard deviations for the six preshock minutes, the six shock minutes, and the disruption scores. Analysis of the difference between RR and SC means clearly indicates that RR Ss were significantly less disrupted than SC Ss $(t=5.4, p<.01)$. Likewise, RR Ss were significantly less disrupted than $C$ Ss $(t=7.13, p<.01)$ and $C$ Ss were significantly more disrupted than $\mathrm{SC} S \mathrm{Ss}(\mathrm{t}=4.6, \mathrm{p}<.01)$. This pattern of results indicates that learning to perform an ongoing, rewarded response during inescapable stress produces less disruption in later inescapable stress situations than experiencing inescapable stress alone or having no prior experience with stress. Also, it is apparent

Table 1

Shock Test Means and Standard Deviations for $6 \mathrm{~min}$ Preshock, $6 \mathrm{~min}$ Shock, and Disruption Scores

\begin{tabular}{|c|c|c|c|c|c|c|c|}
\hline \multirow[b]{2}{*}{ Group } & \multirow[b]{2}{*}{$\mathbf{N}$} & \multicolumn{2}{|c|}{$\begin{array}{c}6 \text { min } \\
\text { Preshock }\end{array}$} & \multicolumn{2}{|c|}{$\begin{array}{c}6 \mathrm{~min} \\
\text { During Shock }\end{array}$} & \multicolumn{2}{|c|}{$\begin{array}{c}\text { Disnuption } \\
\text { Score }\end{array}$} \\
\hline & & Mean & SD & Mean & SD & Mean & SD \\
\hline Rewarded Response (RR) & 10 & 10.87 & 1.70 & 8.24 & 1.04 & 2.63 & 1.22 \\
\hline Shock Control (SC) & 10 & 9.95 & 1.67 & 5.03 & 1.42 & 4.92 & .53 \\
\hline Control (C) + (LC) & 10 & 10.30 & .96 & 2.46 & 1.13 & 7.84 & 1.96 \\
\hline
\end{tabular}


that having experienced gradually increasing intensities of inescapable stress will lead to less disruption in later inescapable stress situations than having no prior experience with stress. The differences between the $\mathrm{SC}$ and the $\mathrm{C}$ groups suggest the operation of an adaptation process which to some extent mitigates against severe disruption. This interpretation may explain in part the differences between the RR and $\mathrm{C}$ groups. The present experiment does not allow for a clearcut choice between the various theoretical possibilities to explain the difference between the RR and $\mathrm{SC}$ groups. It is reasonable to hypothesize that a learned expectancy was acquired by the RR Ss which mediated their more adequate later performance. However, further research is necessary to clarify this hypothesis and to more adequately define the nature of such an expectancy. Whatever the specific mediator may be it seems clear that there is some generality to the process. That is, learning to perform one ongoing rewarded response under inescapable stress will reduce disruption in the performance of a different ongoing rewarded response in later inescapable stress situations. It is important to evaluate how generalizable these present findings are. Currently both responses utilized were appetitive in nature even though considerably different, and in both cases the stressor was electric shock. A more stringent test of the generality of the process or processes operating must involve even greater dissimilarity of responses and stressors. Research aimed at exploring these parameters is now being planned.

\section{REFERENCES}

FARBER, I. E. Response fixation under anxiety and nonanxiety conditions. J. exp. Psychol., 1948, 38, 111-131.

GAURON, E. F. Nature of infantile shock traumatization, strain differences, and adaptability to stress. Psychol. Rep., 1964, 14, 775-779.

OVERMEIR, J. B., \& SELIGMAN, M. E. P. Effects of inescapable shock on subsequent escape and avoidance learning. J. comp. physiol. Psychol, 1967,.63, 28-33.

PAVLOV, I. P. Conditioned reflexes. London: Oxford Univ. Press, 1927.

SELIGMAN, M. E. P., \& MAIER, S. F. Failure to escape traumatic shock. $J$. exp. Psychol., 1967, 74, 1-9.

SHEMBERG, $K$. M. The role of prior learning in performance under stress. Unpublished doctoral dissertation, University of Nebraska, 1966. NOTE

1. This research was partially supported by NIMH grant $13800-01$. 